\title{
Donation after circulatory determination of death in western Canada: a multicentre study of donor characteristics and critical care practices
}

\section{Le don d'organes après décès cardiocirculatoire dans l'Ouest canadien : une étude multicentrique sur les caractéristiques des donneurs et les pratiques de soins intensifs}

\author{
Andreas H. Kramer, MD (D) - Kerry Holliday, MSW • Sean Keenan, MD • George Isac, MD • \\ Demetrios J. Kutsogiannis, MD • Norman M. Kneteman, MD • Adrian Robertson, MD • \\ Peter Nickerson, MD • Lee Anne Tibbles, MD
}

Received: 11 September 2019/Revised: 5 November 2019/Accepted: 20 November 2019/Published online: 25 February 2020

(C) Canadian Anesthesiologists' Society 2020

\begin{abstract}
Purpose Donation after circulatory determination of death (DCD) has been performed in Canada since 2006. Numerous aspects of donor management remain controversial.

Methods We performed a multicentre cohort study involving potential DCD donors in western Canada
\end{abstract}

\section{A. H. Kramer, MD (ه)}

Department of Critical Care Medicine, Foothills Medical Center, University of Calgary, 3132 Hospital Drive N.W, Calgary, AB T2N 5A1, Canada

e-mail: Andreas.Kramer@AlbertaHealthServices.ca

Southern Alberta Organ and Tissue Donation Program,

Alberta Health Services, Calgary, AB, Canada

K. Holliday, MSW

Southern Alberta Organ and Tissue Donation Program,

Alberta Health Services, Calgary, AB, Canada

S. Keenan, MD · G. Isac, MD

Division of Critical Care Medicine, University of British

Columbia, Vancouver, BC, Canada

BC Transplant, Vancouver, BC, Canada

D. J. Kutsogiannis, MD

Department of Critical Care Medicine, University of Alberta,

Edmonton, AB, Canada

Human Organ, Procurement, and Exchange (HOPE) Program, University of Alberta, Edmonton, AB, Canada
(2008-2017), as well as recipients of their organs, to describe donor characteristics and critical care practices, and their relation to one-year recipient and graft survival. Results There were 257 patients in four provinces that underwent withdrawal of life-sustaining therapies (WLST) in anticipation of possible DCD. The proportion of patients that died within two hours of WLST ranged from $67 \%$ to

N. M. Kneteman, MD

Department of Surgery, University of Alberta, Edmonton, AB, Canada

Alberta Transplant Institute, Edmonton, AB, Canada

A. Robertson, MD

Division of Critical Care Medicine, University of Manitoba, Winnipeg, MB, Canada

Transplant Manitoba, Winnipeg, MB, Canada

P. Nickerson, MD

Transplant Manitoba, Winnipeg, MB, Canada

Department of Medicine, University of Manitoba, Winnipeg, MB, Canada

L. A. Tibbles, MD

Southern Alberta Transplant Program, Calgary, AB, Canada

Department of Medicine, University of Calgary, Calgary, AB, Canada 
$88 \%$ across provinces $(P=0.06)$, and was predicted by deeper coma $(P=0.01)$, loss of pupillary light or corneal reflexes $(P=0.02)$, and vasopressor use $(P=0.01)$. There were significant differences between provinces in time intervals from onset of hypotension to death $(9-11 \mathrm{~min}$; $P=0.02)$ and death to vascular cannulation (7-10 min; $P<0.001)$. There was inconsistency in pre-mortem heparin administration (82-96\%; $P=0.03$ ), including timing (before vs after WLST; $P<0.001)$ and dose $(\geq 300$ vs $<300$ units $\left.\cdot \mathrm{kg}^{-1} ; P<0.001\right)$. Donation after circulatory death provided organs for 321 kidney, 81 liver, and 50 lung transplants. One-year recipient and graft survival did not differ among provinces (range 85-90\%, $P=0.45$ ). Predictors of death or graft failure included older recipient age (odds ratio [OR] per year, 1.04; 95\% confidence interval [CI],1.01 to 1.07) and male donor sex (OR, 3.35; 95\% CI, 1.39 to 8.09), but not time intervals between WLST and cannulation or practices related to heparin use.

Conclusion There is significant variability in critical care DCD practices in western Canada, but this has not resulted in significant differences in recipient or graft survival. Further research is required to guide optimal management of potential DCD donors.

\section{Résumé}

Objectif Le don d'organes après décès cardiocirculatoire (DDC) est pratiqué au Canada depuis 2006. De nombreux aspects touchant à la prise en charge des donneurs demeurent controversés.

Méthode Nous avons réalisé une étude de cohorte multicentrique auprès de donneurs potentiels de DDC dans l'Ouest canadien (2008-2017), ainsi qu'auprès des récipiendaires de leurs organes, afin de décrire les caractéristiques des donneurs et les pratiques de soins intensifs, ainsi que la relation entre ces eléments et la survie à un an des récipiendaires et des organes greffés.

Résultats $A u$ total, 257 patients provenant de quatre provinces ont subi une interruption des traitements de survie en vue d'un possible DDC. La proportion de patients décédés dans les deux heures suivant l'interruption des traitements de survie allait de $67 \%$ à $88 \%$ dans toutes les provinces à l'étude $(P=0,06)$ et pouvait être prédite par une profondeur du coma plus importante $(P=0,01)$, la perte de la réaction pupillaire à la lumière ou des réflexes cornéens $(P=0,02)$, et l'utilisation de vasopresseurs $(P=0,01)$. Des différences significatives ont été observées entre les différentes provinces dans les intervalles de temps entre le début de l'hypotension et le décès (9-11 min; $P=0,02)$ et entre le décès et la canulation vasculaire $(7-10 \mathrm{~min} ; P<0,001)$. Il $y$ avait divergence dans l'administration d'héparine avant le décès (82-96\%; $P=0,03)$, notamment en ce qui concerne le moment d'administration (avant vs après l'interruption des traitements de survie; $P<0,001)$ et la posologie $\left(\geq 300 \mathrm{vs}<300\right.$ unités $\left.\cdot \mathrm{kg}^{-1} ; P<0,001\right)$. Le don après décès cardiocirculatoire a permis de procurer des organes pour 321 greffes rénales, 81 greffes hépatiques et 50 greffes pulmonaires. La survie à un an du récipiendaire et du greffon ne différait pas d'une province à l'autre (allant de 85 à $90 \%, P=0,45$ ). Les prédicteurs de décès ou de la défaillance du greffon incluaient l'âge plus avancé $d u$ récipiendaire (rapport de cotes [RC] par année, 1,04; intervalle de confiance [IC] $95 \%, 1,01$ à 1,07) et un donneur de sexe masculin (RC, 3,35; IC $95 \%, 1,39$ à 8,09), mais pas les intervalles de temps entre l'interruption des traitements de survie et la canulation, ni les pratiques liées à l'utilisation d'héparine.

Conclusion Il existe une importante variabilité dans les pratiques de soins intensifs pour le DDC dans l'Ouest canadien, mais cette variabilité n'a pas résulté en différences significatives en matière de survie des récipiendaires ou des greffons. Des recherches supplémentaires sont nécessaires afin d'aiguiller la prise en charge optimale des donneurs potentiels de DDC.

Organ transplantation is the preferred treatment for many patients with end-stage kidney, liver, heart, and lung disease. In Canada, there are over 4,000 patients on transplant waitlists, with between 200 and 300 dying each year without receiving a transplant. ${ }^{1}$ The most common source of deceased organ donation is critically ill, braininjured patients that deteriorate to the point of complete and permanent cessation of all cerebral functions, at which point criteria are met for neurologic determination of death (NDD) or "brain death"., ${ }^{2,3}$ The proportion of severely brain-injured patients that die in this manner has decreased significantly over time. ${ }^{4}$

Donation after circulatory determination of death (DCD) has been performed in Canada since 2006 and represents a growing source of organs for transplantation, but adoption across the country has been gradual and variable. ${ }^{5}$ Numerous aspects of DCD remain controversial, such as criteria used to define death and the need for certain premortem interventions that are of no direct clinical benefit to the donor. ${ }^{6,7}$ Although national guidelines exist, best practices among potential donors are not based on a high level of evidence. ${ }^{8-13}$

Guidelines for the care of NDD organ donors exist to maintain physiologic parameters (e.g., mean arterial pressure, partial pressure of oxygen, and urine output) within certain "donor management goals", which in turn have been associated with a greater number of organs 
transplanted per donor and improved early graft function in recipients. ${ }^{14-16}$ Because potential DCD donors are not yet deceased during workup for transplantation, the appropriateness of targeting physiologic goals for the purpose of graft optimization is controversial. Donor management goals are largely not addressed in national guidelines. $^{8-13}$

Previous surveys have reported variability in DCD protocols in the United States and Europe. ${ }^{17,18}$ Comparative observational studies between regions have not been performed and relatively little is known about potential implications of such practice variability on outcomes of transplant recipients. ${ }^{19}$ We performed a retrospective, multi-provincial cohort study involving all consecutive DCD donors in western Canada between 2008 and 2017, as well as recipients of their organs. The primary purpose was to describe variability in current DCD practices and associations with patient and graft survival.

\section{Methods}

This study was a collaborative effort between organ donation organizations (ODOs) and transplant programs in the four western Canadian provinces: BC Transplant, the Human Organ Procurement and Exchange Program (Northern Alberta), the Southern Alberta Organ and Tissue Donation Program, the Southern Alberta Transplant Program, the Saskatchewan Transplant Program, and Transplant Manitoba. Financial support was provided by the Alberta Organ and Tissue Donation Agency, a branch of Alberta Health. The study was approved by research ethics boards in each of the provinces.

We accessed the databases of each ODO and transplant program to identify patients for whom consent for DCD had been provided between 2008 and the end of 2017 (extended to June 2018 in southern Alberta only), as well as recipients of their organs. Patients' electronic and paperbased medical records were reviewed. In Alberta, all intensive care units (ICUs) use a common clinical information system (Meta-Vision Data, iMD Soft, Israel) that records minute-by-minute vital signs. Variables were extracted using standardized forms that were developed $a$ priori by iterative consensus among investigators.

Characteristics of potential and actual (from whom at least one organ was transplanted) donors were compared across regions. Variables of interest included donor age, sex, body mass index (BMI), cause of death, conversion from potential to actual donor, various time intervals during progression from withdrawal of life-sustaining therapies (WLST) to organ cannulation in the operating room (WLST to cannulation, hypoxemia to cannulation, hypotension to cannulation, and death to cannulation were all analyzed separately), and use of heparin in donors (including timing and dose). In patients receiving multiple modalities of life-sustaining therapies, the time of extubation was considered to be the time at which WLST occurred. Sustained hypoxemia was defined a priori as arterial oxygen saturation consistently less than $70 \%$. Sustained hypotension was defined according to criteria used at individual centres, which was either systolic blood pressure less than $60 \mathrm{mmHg}$ or mean arterial pressure less than $50 \mathrm{mmHg}$. These definitions are used by western Canadian centres to define the onset of "functional warm ischemia time", consistent with British Transplantation Society Guidelines. ${ }^{13}$ This information was recorded prospectively, particularly in the latter part of the study period. We compared the last documented neurologic examination findings and physiologic support requirements among potential donors based on whether or not they died within two hours of WLST, which is generally the requisite timeframe for DCD to occur in Canada. ${ }^{5,8,9}$ In transplant recipients, we determined the composite of one-year patient and graft survival, and its association with donor characteristics. Graft survival was considered to be present if kidney recipients did not need renal replacement therapy and liver or lung recipients were not re-listed or retransplanted.

Categorical variables were compared using Chi square analysis or Fisher's exact test, as appropriate. Continuous variables were reported as medians [interquartile ranges (IQR)] and compared using Kruskall-Wallis tests. The number of organs transplanted per donor was reported as mean (standard deviation [SD]). Logistic regression was used to assess associations between donor characteristics and patient and graft outcomes. Multivariable models included all relevant donor variables (age, sex, BMI, cause of death, time from WLST to cannulation, and heparin use) as well as recipient variables that were statistically significant in univariate analysis. Models were also fit using the generalized estimating equation method to account for correlated, hierarchical data (more than one organ donated per donor). Non-significant variables were removed one by one from multivariable models using a backwards elimination approach. All analyses were performed using SAS (Version 9.4, Cary, NC, USA). $P$ values less than 0.05 were considered statistically significant.

\section{Results}

Donor characteristics

There were 272 patients from 22 different hospitals from whom consent for DCD was provided (Table 1). Of these, 
TABLE 1 Characteristics of patients that underwent withdrawal of life-sustaining therapy with the possibility of DCD in Western Canada 2008-2018

Alberta $(n=68) \quad$ British Columbia $(n=171) \quad$ Manitoba / Saskatchewan $(n=18) \quad P$ value

\begin{tabular}{|c|c|c|c|c|}
\hline \multicolumn{5}{|l|}{ Donor characteristics } \\
\hline Age (yr), median [IQR] & $47[31-56]$ & $49[36-58]$ & 49 [39-56] & 0.21 \\
\hline Female sex & $22(32)$ & $51(30)$ & $7(39)$ & 0.72 \\
\hline Body mass index, median [IQR] & $27[23-32]$ & 26 [24-29] & $25[22-34]$ & 0.38 \\
\hline \multicolumn{5}{|l|}{ Cause of death } \\
\hline HIBI & $28(41)$ & $84(49)$ & $3(17)$ & \multirow[t]{5}{*}{0.02} \\
\hline Cerebrovascular & $22(32)$ & $35(20)$ & $2(11)$ & \\
\hline TBI & $13(19)$ & $28(16)$ & $7(39)$ & \\
\hline Other & $5(7)$ & $24(14)$ & $2(11)$ & \\
\hline Unrecorded & 0 & 0 & $4(22)$ & \\
\hline \multicolumn{5}{|l|}{ Past medical history } \\
\hline Diabetes mellitus & $6(9)$ & $9(5)$ & $1(6)$ & 0.47 \\
\hline Hypertension & $16(24)$ & $32(19)$ & $1(6)$ & 0.23 \\
\hline Smoking & $30(44)$ & $89(52)$ & $7(39)$ & 0.36 \\
\hline Drug abuse & $17(25)$ & $75(44)$ & $7(39)$ & 0.02 \\
\hline Exceptional distribution status ${ }^{1}$ & $30(44)$ & $73(43)$ & $9(50)$ & 0.83 \\
\hline Registered donor & $8(12)$ & $42(25)$ & $2(11)$ & $<0.0001$ \\
\hline \multicolumn{5}{|l|}{ WLST to organ procurement/transplantation } \\
\hline Life-sustaining therapies at end of life & $68(100)$ & $171(100)$ & $18(100)$ & 1.00 \\
\hline Invasive mechanical ventilation & $29(43)$ & $36(21)$ & $5(28)$ & 0.003 \\
\hline Vasopressors and/or inotropes & $2(3)$ & $2(1)$ & 0 & 0.52 \\
\hline \multicolumn{5}{|l|}{ Extracorporeal support } \\
\hline WLST in ICU & $66(97)$ & $165(96)$ & $17(94)$ & 0.41 \\
\hline Death within $2 \mathrm{hr}$ WLST & $60(88)$ & $131(77)$ & $12(67)$ & 0.06 \\
\hline$\geq 1$ organ transplanted & $57(84)$ & $129(75)$ & $11(61)$ & 0.10 \\
\hline Organs per actual donor, mean (SD) & $2.3(1.4)$ & $2.6(1.6)$ & $1.5(0.9)$ & 0.01 \\
\hline \multicolumn{5}{|l|}{ Time intervals (min), median [IQR] } \\
\hline WLST to cannulation & $33[29-40]$ & $28[23-37]$ & $29[21-52]$ & 0.02 \\
\hline WLST to hypoxemia & $3[2-5]$ & $4[2-11]$ & $2.5[0-6]$ & 0.03 \\
\hline Hypoxemia to hypotension & $5[2-9]$ & $5[2-11]$ & $2[0-5]$ & 0.15 \\
\hline Hypotension to death & $10[8-16]$ & $9[7-11]$ & $11[9-20]$ & 0.02 \\
\hline Death to cannulation & $10[9-13]$ & $7[6-9]$ & $8[8-12]$ & $<0.001$ \\
\hline \multicolumn{5}{|l|}{ Anticoagulation } \\
\hline Heparin administered (potential donors) & $55 / 65(85)$ & $128 / 160(80)$ & $15 / 17(88)$ & 0.56 \\
\hline Heparin administered (actual donors) & $48 / 56(86)$ & $115 / 120(96)$ & $9 / 11(82)$ & 0.03 \\
\hline WLST to heparin (min), median [IQR] & $4[0-10]$ & $4[0-10]$ & $0[0-0]$ & $<0.001$ \\
\hline Heparin timing & & & & $<0.001$ \\
\hline Before or concomitant with WLST & $16 / 53(30)$ & $35 / 121(29)$ & $13 / 13(100)$ & \\
\hline Following WLST & $37 / 53(70)$ & $86 / 121(71)$ & 0 & \\
\hline Heparin dose (when given) & & & & $<0.001$ \\
\hline$\geq 300$ units $/ \mathrm{kg}$ & 13/64 (20) & $111 / 157$ (71) & $14 / 16(88)$ & \\
\hline$<300$ units $/ \mathrm{kg}$ & $51 / 64(80)$ & 46/157 (29) & 2/16 (13) & \\
\hline
\end{tabular}

Data are presented as $n(\%)$ unless otherwise indicated.

$\mathrm{DCD}$ = donation after circulatory determination of death; HIBI = hypoxic-ischemic brain injury; ICU = intensive care unit; IQR = interquartile range; $\mathrm{SD}=$ standard deviation; $\mathrm{TBI}=$ traumatic brain injury; WLST $=$ withdrawal of life-sustaining therapy.

${ }^{1}$ Exceptional distribution $=$ cases where organs are recovered and transplanted despite relative contraindications, as defined by Canadian Standards Association. 
$15(6 \%)$ progressed to NDD during preparations for DCD and ultimately became "heart beating" NDD donors. A mean (SD) of 4.8 (1.2) organs were transplanted from these 15 NDD donors, including five heart transplants. Status change from potential DCD to NDD donor was only systematically recorded in one province (Alberta), such that our data underestimates this phenomenon.

Of the remaining 257 patients that underwent WLST with the possibility of DCD, 171 (67\%) were from British Columbia, 68 (26\%) from Alberta, and 18 (7\%) from Saskatchewan or Manitoba. DCD activity increased markedly over the latter part of the first decade, with 85\% of potential donors dying in 2013-2017 rather than 2008-2012 (Fig. 1). Age, sex, and BMI of potential donors did not differ significantly between regions. The most common cause of death was hypoxic-ischemic brain injury (HIBI), although there was a relatively higher proportion of donors dying from traumatic brain injury in Saskatchewan/ Manitoba $(P=0.02)$. British Columbia had the highest proportion of potential donors with a history of drug abuse $(P=0.02)$ and that had declared an intent to donate in a provincial registry $(P<0.001)$.

Time Intervals from Withdrawal of Life-Sustaining Therapy to Organ Procurement

In almost all cases, WLST occurred in an ICU rather than an operating room. Differences in the proportion of potential donors dying within two hours of WLST approached statistical significance, ranging from $67 \%$ (Saskatchewan/Manitoba) to $88 \%$ (Alberta) $(P=0.06)$ (Table 1). The proportion in whom at least one organ was recovered and transplanted ranged from $61 \%$ to $84 \%(P=$ $0.10)$. Non-utilization of organs was uncommon when patients died within two hours of WLST. The mean (SD) number of organs procured and transplanted per donor was 1.5 (0.9) in Saskatchewan and Manitoba (where liver and

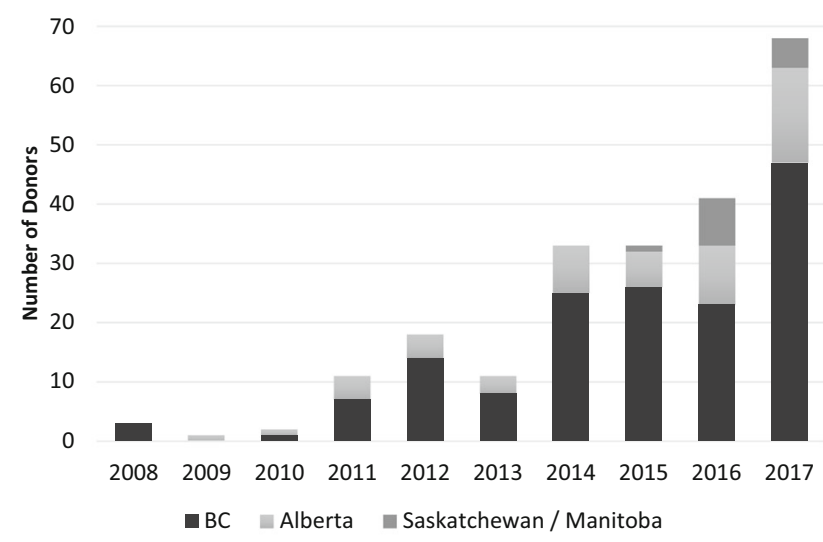

Fig. 1 First decade of donation after circulatory determination of death in western Canada. lung donation were not performed), compared with 2.3 (1.4) in Alberta and 2.6 (1.6) in British Columbia $(P=$ $0.01)$.

Among 196 actual DCD donors, times of WLST, onset of hypoxemia (pulse oximetry $<70 \%$ ), onset of hypotension (systolic blood pressure $<60 \mathrm{mmHg}$ or mean arterial pressure $<50 \mathrm{mmHg}$ ), death, and cannulation were documented in $98 \%, 73 \%, 77 \%, 99 \%$, and $85 \%$, respectively. The median [IQR] time from WLST to cannulation and cold perfusion of organs in the operating room was 33 [29-40] min in Alberta, compared with 28 [23-37] min in British Columbia and 29 [21-52] min in Saskatchewan and Manitoba $(P=0.02)$. The greater total duration in Alberta was attributable to a longer duration from onset of hypotension to declaration of death $(P=0.02)$ and time from declaration of death to vascular cannulation $(P<0.001)$.

\section{Anticoagulation in potential DCD donors}

Heparin was administered in $82 \%$ of potential DCD donors (range across provinces $80-100 \%$ ) (Table 1). Heparin was routinely given at the time of (or prior to) WLST in Manitoba, but was not used in Saskatchewan donors. In Alberta and British Columbia, heparin administration was often delayed until some point between WLST and death. The median [IQR] time from WLST to heparin administration was 4 [0-10] min. In 59\% of cases, heparin was given after the onset of sustained arterial oxygen saturation below $70 \%$. In $39 \%$ of cases, it was given after the onset of sustained hypotension (systolic pressure $<60 \mathrm{mmHg}$ or mean arterial pressure $<50$ $\mathrm{mmHg}$ ). When hypoxemia and hypotension did not occur, heparin was frequently withheld. Accordingly, heparin was given to only $39 \%$ of patients that did not die within two hours of WLST in Alberta and British Columbia, compared with all such patients in Manitoba. The dose of heparin ranged from 74 units $\cdot \mathrm{kg}^{-1}$ to 667 units $\cdot \mathrm{kg}^{-1}$. It was usually $\geq 300$ units $\cdot \mathrm{kg}^{-1}$ in Manitoba and British Columbia, with lower doses used predominantly in Alberta $(P<0.001)$, but there was also considerable variability within regions. When heparin was given to patients that died within two hours of WLST, the median [IQR] number of organs transplanted was 3 [2-4], compared with 3 [2-4] when heparin was not given $(P=0.88)$.

Prediction of death

Neurologic examination findings were inconsistently documented in the medical records (Table 2). When recorded, patients dying within two hours of WLST were more deeply comatose (Glasgow Coma Scale [GCS] score $3-4$ in $76 / 80$ [95\%] vs $12 / 16$ [75\%], $P=0.008$ ), and more 
TABLE 2 Comparison of findings based on whether potential DCD donors died within two hours of withdrawal of life-sustaining therapy

\begin{tabular}{llll}
\hline & Death within 2 hr WLST $(n=203)$ & Death greater than 2 hr following WLST $(n=54)$ & $P$ value \\
\hline GCS 3-4 & $76 / 80(95)$ & $12 / 16(75)$ & 0.01 \\
Bilateral absent pupillary light reflexes & $64 / 108(59)$ & $6 / 20(30)$ & 0.02 \\
Bilateral absent corneal reflexes & $72 / 97(74)$ & $6 / 14(43)$ & 0.02 \\
Absent oculocephalic reflex & $30 / 36(83)$ & $4 / 6(67)$ & $12 / 21(57)$ \\
Absent gag reflex & $66 / 91(73)$ & $6 / 19(32)$ & 0.34 \\
Absent cough reflex & $47 / 90(52)$ & $7 / 54(13)$ & 0.17 \\
Vasopressor or inotrope & $63 / 203(31)$ & $374[245-447]$ & 0.10 \\
$\mathrm{P}_{\mathrm{a}} \mathrm{O}_{2}: \mathrm{F}_{\mathrm{I}} \mathrm{O}_{2}$, median $[\mathrm{IQR}]$ & $352[271-438]$ &
\end{tabular}

Data are presented as $n(\%)$ unless otherwise indicated.

DCD = donation after circulatory determination of death; $\mathrm{F}_{\mathrm{I}} \mathrm{O}_{2}=$ fraction of inspired oxygen; GCS = Glasgow Coma Scale; $\mathrm{P}_{\mathrm{a}} \mathrm{O}_{2}=$ partial pressure of oxygen; WLST $=$ withdrawal of life-sustaining therapy.

likely to have bilateral absence of pupillary light reflexes (64/108 [59\%] vs 6/20 [30\%], $P=0.02)$ and corneal reflexes $(72 / 97$ [74\%] vs 6/14 [43\%], $P=0.02)$. Similar trends were observed with oculocephalic, gag, and cough reflexes, but the differences did not reach statistical significance when individual brainstem reflexes were assessed. When at least two brainstem reflexes were recorded as being absent, death occurred within two hours in $90 \%$ of cases, compared with $73 \%$ when this was not the case $(P=0.002)$. Vasopressors were used immediately prior to WLST in 63/203 (31\%) of patients dying within two hours compared with only $7 / 54(13 \%)$ of those that did not die in this timeframe $(P=0.01)$. There was no difference in pre-extubation partial pressure of oxygen and fraction of inspired oxygen between groups. Because of the sizable number of patients where neurological findings were not documented, we did not perform a multivariable analysis. Potential donors in Alberta and British Columbia were more likely to have a GCS score of 3-4 (98\% in Alberta, 97\% in British Columbia, and $60 \%$ in Saskatchewan and Manitoba; $P<$ $0.001)$ and bilateral loss of pupillary light reflexes $(63 \%$ in Alberta, $57 \%$ in British Columbia, and $14 \%$ in Saskatchewan and Manitoba; $P=0.01$ ). Potential donors in Alberta had the highest rate of vasopressor use prior to WLST (43\% in Alberta, 21\% in British Columbia, and $28 \%$ in Manitoba; $P=0.003$ ).

Donation after circulatory death transplants and outcomes

There were 321 kidney, 81 liver, and 50 lung transplants performed in western Canada using organs procured from DCD donors that died in western Canada (Fig. 2). Oneyear patient and graft survival rates were $90 \%$ for kidney, $83 \%$ for liver, and $90 \%$ for lung transplantation (Table 3).

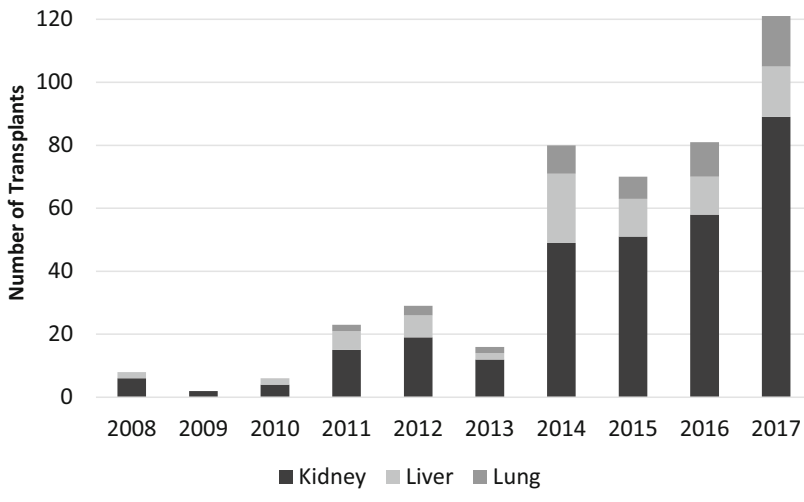

Fig. 2 First decade of transplantation using organs procured following donation after circulatory determination of death in western Canada. *Does not include organs that were imported from other provinces.

There were no statistically significant differences in patient and graft survival rates between provinces, either for individual organ subtypes or for all transplants in combination.

Recipients that died or had graft loss within one year were generally older (median [IQR] age 63 [50-70] yr vs 58 [45-65] yr, $P=0.01)$ and more likely to have received an organ from a male donor $(88 \%$ vs $69 \%, P=0.005)$ (Table 4). Recipient and graft survival rates were $99 \%$ for female to male, $90 \%$ for female to female, $87 \%$ for male to male, and $84 \%$ for male to female donations $(P=0.01)$. Patient and graft survival at one year were not associated with any of the following time intervals: WLST to organ cannulation; sustained arterial oxygen saturation $<70 \%$ to organ cannulation; sustained hypotension (systolic pressure $<60 \mathrm{mmHg}$ or mean pressure $<50 \mathrm{mmHg}$ ) to organ cannulation; or death to organ cannulation. Similarly, patient and graft survival were not associated with heparin use (compared with withholding of heparin), timing of 
Table 3 One-year patient and graft survival in recipients of organ transplants following DCD ${ }^{1}$

\begin{tabular}{lllll}
\hline Organ subtype & Alberta $(n=117)$ & British Columbia $(n=314)$ & Manitoba / Saskatchewan $(n=19)$ & $P$ value \\
\hline Kidney & $73 / 85(86)$ & $197 / 215(92)$ & $17 / 19(89)$ & 0.33 \\
Liver & $12 / 14(86)$ & $55 / 67(82)$ & 0 & 0.74 \\
Lung $^{1}$ & $14 / 16(88)$ & $30 / 32(94)$ & $17(89)$ & 0.46 \\
Total & $100(85)$ & $282(90)$ & & 0.45 \\
\hline
\end{tabular}

Data are presented as $n(\%)$.

$\mathrm{DCD}=$ donation after circulatory determination of death.

${ }^{1}$ There were also two lung transplants performed in Ontario from Western Canadian DCD donors that are not included in the Table.

administration, or dose (either as a dichotomized or continuous variable).

In multivariable analysis, older recipient age (odds ratio $[\mathrm{OR}]$ per year, $1.04 ; 95 \%$ confidence interval $[\mathrm{CI}], 1.01$ to $1.07 ; P=0.001)$ and donor male sex $(\mathrm{OR}, 3.35 ; 1.39-8.09$; $P=0.009)$ remained independently associated with oneyear mortality or graft failure after adjustment for other donor characteristics (age, sex, BMI, cause of death, time from WLST to cannulation, and heparin administration).

\section{Discussion}

This report describes the first decade of DCD activity in western Canada. Adoption of DCD was slow in the first half of the decade, but increased substantially in the latter half, resulting in more than 400 transplants, with 85-90\% of recipients alive with functioning grafts after one year.

Our study provides a comprehensive description of the characteristics of DCD donors in western Canada. Most donors die from the same conditions that lead to NDD, most often HIBI, followed by traumatic brain injury and various forms of stroke. ${ }^{20}$ When consent is obtained for DCD, it is important to consider and identify the possibility of subsequent progression to NDD, since a larger number of organs can be procured per donor. A high rate of donors with a history of drug abuse likely reflects the recent opiate crisis, which has affected British Columbia more than other Canadian provinces. ${ }^{21}$ British Columbia donors more often provided first-person consent for donation, likely because British Columbia had a provincial registry before other provinces did (1997 in British Columbia; 2014 in Alberta; and 2019 in Saskatchewan and Manitoba).

Unlike many centres in the United States and other parts of Canada, WLST occurred almost invariably in an ICU rather than an operating room. While the latter reduces warm ischemic time, the ICU is commonly regarded as more suitable for end of life care, particularly when patients do not die within the requisite time frame for DCD to proceed. Because of the small number of donors that underwent WLST in an operating room, we were unable to assess the effect of location on one-year graft outcomes. Although limitation of warm ischemic time is important, existing literature has not shown any clear improvement in recipient outcomes when WLST occurs in an operating room. ${ }^{22}$

The proportion of potential donors that died within two hours of WLST varied across regions. This likely relates to selection criteria, since potential donors in the region with the highest rate (Alberta) were also significantly more likely to have a GCS score of 3-4, bilateral loss of pupillary light reflexes, and need for vasopressors prior to WLST, all of which were associated with a greater chance of death within two hours following WLST. These predictors are consistent with previous literature. ${ }^{23-26}$ Nevertheless, there are relatively few published studies specifically involving brain-injured patients, using a time frame of two hours rather than one hour, and conducted exclusively among potential DCD donors (rather than critically ill patients in general). ${ }^{23-26}$ These data are important to provide guidance to clinicians and families in decision-making regarding DCD. From the perspective of patients and their families, the opportunity to donate organs may be very important. Nevertheless, delays in end of life care to facilitate DCD may also be difficult to accept and tolerate, especially when there is uncertainty that organs will even be procured after these delays. ${ }^{27}$ Moreover, cases where patients do not die consume substantial resources despite no resultant organ transplants. We did not have data from neuroimaging, which has also been shown to predict the time from WLST to death. ${ }^{28,29}$

Death following WLST usually involves a relatively predictable sequence of events, beginning with hypoxemia, followed by hypotension, loss of pulse pressure, and eventual (electrical) asystole. Nevertheless, the onset and relative duration of these time intervals are less predictable. Time from WLST to vascular cannulation in the operating room was longer in Alberta than in other provinces. This observation was due, in part, to a longer duration from onset of hypotension to death. In Alberta and Saskatchewan, electrical asystole was required, while in 
Table 4 Patient characteristics based on recipient and graft survival following DCD

\begin{tabular}{|c|c|c|c|}
\hline & Recipient/graft survival ( $n=399)$ & Recipient/graft non-survival $(n=51)$ & $P$ value \\
\hline \multicolumn{4}{|l|}{ Donor characteristics } \\
\hline Age (yr), median [IQR] & $47[32-55]$ & $52[33-60]$ & 0.11 \\
\hline Female sex & $123(31)$ & $6(12)$ & 0.01 \\
\hline \multicolumn{4}{|l|}{ Cause of death } \\
\hline HIBI & $169(42)$ & $23(45)$ & \multirow[t]{4}{*}{0.92} \\
\hline TBI & $96(24)$ & $12(24)$ & \\
\hline Cerebrovascular & $82(21)$ & $11(22)$ & \\
\hline Other & $52(13)$ & $5(10)$ & \\
\hline Body mass index, median [IQR] & 26 [23-29] & 27 [23-29] & 0.60 \\
\hline \multicolumn{4}{|l|}{ Past medical conditions } \\
\hline Diabetes mellitus & $21(5)$ & $5(10)$ & 0.19 \\
\hline Hypertension & $66(17)$ & $9(18)$ & 0.84 \\
\hline Smoking & $204(51)$ & $21(41)$ & 0.19 \\
\hline \multicolumn{4}{|l|}{ Time period } \\
\hline 2008-2012 & $60(15)$ & $7(14)$ & \multirow[t]{2}{*}{0.80} \\
\hline 2013-2017 & $339(85)$ & $44(86)$ & \\
\hline \multicolumn{4}{|l|}{ Recipient characteristics } \\
\hline Age $(\mathrm{yr})$, median [IQR] & $58[45-65]$ & $63[50-70]$ & 0.01 \\
\hline Female sex & $127(32)$ & $20(39)$ & 0.29 \\
\hline Body mass index, median [IQR] & $26[23-31]$ & $27[23-31]$ & 0.66 \\
\hline Cold ischemia time (min), median [IQR] & $433[335-639]$ & $412[353-621]$ & 0.93 \\
\hline Ex vivo organ support system & $128(32)$ & $11(22)$ & 0.13 \\
\hline \multicolumn{4}{|l|}{ WLST to organ procurement/transplantation } \\
\hline \multicolumn{4}{|l|}{ Time intervals (min), median [IQR] } \\
\hline WLST to cannulation & $28[23-35]$ & $31[26-36]$ & 0.25 \\
\hline Hypoxia to cannulation & $24[18-33]$ & $24[18-35]$ & 0.66 \\
\hline Hypotension to cannulation & $18[15-24]$ & $19[15-23]$ & 0.91 \\
\hline Death to cannulation & $8[6-10]$ & $8[6-10]$ & 0.93 \\
\hline \multicolumn{4}{|l|}{ Anticoagulation } \\
\hline Heparin administration & $343 / 373(92)$ & $45 / 48(94)$ & 0.66 \\
\hline \multicolumn{4}{|l|}{ Heparin timing } \\
\hline Before or concomitant with WLST & $93 / 351(26)$ & 9/48 (19) & 0.25 \\
\hline Following WLST & $258 / 351(74)$ & $39 / 48(81)$ & \\
\hline \multicolumn{4}{|l|}{ Heparin dose } \\
\hline$\geq 300$ units $/ \mathrm{kg}$ & $241 / 333(72)$ & $31 / 45(69)$ & 0.63 \\
\hline$<300$ units $/ \mathrm{kg}$ & $92 / 333(28)$ & $14 / 45(31)$ & \\
\hline
\end{tabular}

Data are presented as $n(\%)$ unless otherwise indicated.

$\mathrm{DCD}=$ donation after circulatory determination of death; HIBI = hypoxic-ischemic brain injury; ICU = intensive care unit; IQR = interquartile range; TBI = traumatic brain injury; WLST = withdrawal of life-sustaining therapy.

British Columbia and Manitoba, five minutes of pulse pressure absence was sufficient to declare death. Such variability has also been observed in other parts of the world, ${ }^{17,18}$ and is based on concerns about the potential for autoresuscitation, ${ }^{30}$ as well as a desire by some critical care professionals to remain consistent with criteria used to declare death when critically ill patients are not undergoing DCD (where survey data show that waiting for electrical asystole is common practice). ${ }^{31,32}$ The results of the recently completed Death Prediction and Physiology after Removal of Therapy (DePPaRT) study will provide much needed prospective data regarding the frequency and timing of autoresuscitation. ${ }^{33}$ The DePPaRT pilot study reported resumption of arterial blood pressure after transient cessation for more than $60 \mathrm{sec}$ in four out of 30 patients $(13 \%)$, with the longest temporary pause lasting 89 
sec. ${ }^{34}$ Such data raises concerns about a time threshold of as little as two minutes without pulse pressure that is used at many institutions and is endorsed in guidelines. ${ }^{11}$ The time interval from declaration of death to vascular cannulation was also longest in Alberta. Reasons for this observation are not clear, and could include greater distance from ICUs to operating rooms or greater delays during procurement surgery. Every effort should be made to shorten this time interval, particularly when WLST occurs outside of an operating room.

Administration of heparin to potential DCD donors is controversial in some regions, particularly among patients with intracranial hemorrhage, where anticoagulation would otherwise be absolutely contraindicated because hematoma expansion or recurrent hemorrhage is possible. Although considered necessary by many transplant clinicians, ${ }^{11}$ anticoagulation is regarded as unethical and illegal in some jurisdictions, including countries that have high rates of DCD with favourable outcomes in transplant recipients, such as the United Kingdom and parts of Australia. ${ }^{12,35,36}$ There are no clinical trials assessing use of heparin in DCD and results from observational studies are inconclusive. ${ }^{22,37}$ Animal studies do not show significant microvascular thrombosis when heparin is withheld. ${ }^{38,39}$

The variability we observed in use of heparin in western Canada reflects these controversies. Although heparin was administered in the majority of cases, a common strategy was for critical care teams to wait until physiologic instability occurred, at which point it was very likely that the potential donor would actually die within two hours. This practice often avoids using anticoagulation in patients that do not ultimately become DCD donors. Nevertheless, implications of this strategy on graft function have never been assessed.

Despite significant interprovincial variability in donor characteristics, time intervals between WLST and cannulation, and use of anticoagulation, there were no statistically significant differences between provinces in one-year patient and graft survival rates. While these findings are encouraging, in this study we did not assess early complications following DCD, such as delayed graft function in kidney transplantation or ischemic cholangiopathy in liver transplantation, where previous studies have suggested that warm ischemic time is predictive of complications. ${ }^{40-47}$ The importance of increasing warm ischemic time and heparin may vary by organ. With lung transplantation in particular, prolonged warm ischemic time appears to have less of a detrimental effect. $^{48}$ Decision-making regarding use of organs from DCD donors is complex, with transplant teams considering multiple inter-related factors. Thus, there may not have been sufficient variability in our cohort and relative lack of statistical power to detect an effect of increasing warm ischemic time or heparin use on one-year graft function.

Consistent with previous reports, patient and graft survival rates were worse in older recipients. ${ }^{49}$ There was also a greater chance of death or graft failure among recipients of organs from male donors. This is a novel finding in the context of DCD, and the reasons for this observation are not clear. Recent experimental work has suggested that female kidneys may be less susceptible to ischemia-reperfusion injury. ${ }^{50}$ Analyses of large databases (consisting largely of NDD donors) reported that female donor sex was associated with a lower rate of delayed renal graft function. ${ }^{51,52}$ It has been speculated that $\mathrm{H}-\mathrm{Y}$ antigen mismatch may have a role. ${ }^{51,52}$ Given the importance of ischemia-reperfusion in DCD transplantation, the implications of sex mismatch may be more pronounced than after NDD donation. Nevertheless, these observations require confirmation in other cohort studies.

Strengths of our study include the multi-provincial and multicentre design, with inclusion of all consecutive donors and recipients across a large geographic region. Limitations not already mentioned above include that data collection was largely retrospective and that some variables (e.g., neurologic examination prior to WLST and various time intervals from WLST to cannulation) were inconsistently documented. We also do not have data regarding missed donation opportunities and consent rates for DCD during the study period, although a related study assessing donation potential in western Canada was recently published. $^{53}$

\section{Conclusion}

There has been a gradual, but marked, increase in DCD activity in western Canada over the past decade. There are significant interprovincial differences in donor characteristics, time intervals from WLST to organ procurement, and use of pre-mortem anticoagulation, but this variability was not associated with any clear differences in one-year recipient and graft survival (effects on early post-transplant complications require further investigation). Patient and graft survival rates were higher among younger recipients and when organ donors were female. More research is needed to guide DCD practices, with the aim of maximizing donation opportunities, optimizing recipient outcomes, and ensuring that excellent end of life care in donors is not compromised.

Author contributions Andreas H. Kramer and Lee Anne Tibbles were involved in all aspects of this study (planning, application for funding, collecting data, analyzing and interpreting data, writing the 
manuscript). Kerry Holliday was involved in planning the study and collecting data. Sean Keenan, George Isac, Demetrios J. Kutsogiannis, Norman M. Kneteman, Adrian Robertson, and Peter Nickerson were involved in planning the study, interpreting data, and writing the manuscript.

Disclosures Drs. Kramer, Keenan, and Robertson are medical directors of organ donation agencies in their respective jurisdictions. Dr. Kutsogiannis is the former medical director of the Human Organ Procurement and Exchange Program in Northern Alberta. Drs. Kneteman and Nickerson are medical directors of transplant programs in their respective jurisdictions.

\section{Conflicts of interest None.}

Funding statement This study was funded by a grant from the Alberta Organ and Tissue Donation Agency, a branch of Alberta Health (Government of Alberta).

Editorial responsibility This submission was handled by Dr. Sangeeta Mehta, Associate Editor, Canadian Journal of Anesthesia.

\section{References}

1. Canadian Blood Services. Call to action: a strategic plan to improve organ and tissue donation and transplantation performance in Canadians. Available from URL: https://blood. ca/sites/default/files/otdt-indx-final-c2a.pdf (accessed November 2019).

2. Shemie SD, Doig C, Dickens B, et al. Severe brain injury to neurological determination of death: Canadian forum recommendations. CMAJ 2006; 174: S1-13.

3. Wijdicks EF, Varelas PN, Gronseth GS, Greer DM; American Academy of Neurology. Evidence-based guideline update: determining brain death in adults: report of the Quality Standards Subcommittee of the American Academy of Neurology. Neurology 2010; 74: 1911-8.

4. Kramer AH, Zygun DA, Doig CJ, Zuege DJ. Incidence of neurologic death among patients with brain injury: a cohort study in a Canadian health region. CMAJ 2013; 185: E838-45.

5. Hernandez-Alejandro $R$, Wall W, Jevnikar A, et al. Organ donation after cardiac death: donor and recipient outcomes after the first three years of the Ontario experience. Can J Anesth 2011; 58: 599-605.

6. Squires JE, Graham N, Coughlin M, et al. Barriers and enablers to organ donation after circulatory determination of death: a qualitative study exploring the beliefs of frontline intensive care unit professionals and organ donor coordinators. Transplant Direct 2018; DOI: https://doi.org/10.1097/TXD.0000000000000805.

7. Mandell MS, Zamudio S, Seem D, et al. National evaluation of healthcare provider attitudes toward organ donation after cardiac death. Crit Care Med 2006; 34: 2952-8.

8. Shemie SD, Baker AJ, Knoll G, et al. Donation after cardiocirculatory death in Canada. CMAJ 2006; DOI: https:// doi.org/10.1503/cmaj.060895.

9. Weiss MJ, Hornby L, Rochwerg B, et al. Canadian guidelines for controlled pediatric donation after circulatory determination of death - Summary report. Pediatr Crit Care Med 2017; 18: 103546.

10. Bernat JL, D'Alessandro AM, Port FK, et al. Report of a national conference on donation after cardiac death. Am J Transplant 2006; 6: 281-91.
11. Reich DJ, Mulligan DC, Abt PT, et al. ASTS recommended practice guidelines for controlled donation after cardiac death organ procurement and transplantation. Am J Transplant 2009; 9: 2004-11.

12. The Intensive Care Society, British Transplantation Society, Department of Health, NHS Blood and Transplant. Donation after Circulatory Death. Available from URL: https://www.odt. nhs.uk/deceased-donation/best-practice-guidance/donation-aftercirculatory-death/ (accessed November 2019).

13. British Transplantation Society. Transplantation from deceased donors after circulatory death. Available from URL: https://bts. org.uk/wp-content/uploads/2016/09/15_BTS_Donors_DCD-1. pdf (accessed November 2019).

14. Kotloff RM, Blosser S, Fulda GJ, et al. Management of the potential organ donor in the ICU: Society of Critical Care Medicine / American College of Chest Physicians / Association of Organ Procurement Organizations Consensus Statement. Crit Care Med 2015; 43: 1291-325.

15. Shemie SD, Ross H, Pagliarello J, et al. Organ donor management in Canada: recommendations of the forum on Medical Management to Optimize Donor Organ Potential. CMAJ 2006; 174: S13-32.

16. Malinoski DJ, Patel MS, Daly MC, Oley-Graybill C, Salim A; UNOS Region 5 DMG Workgroup. The impact of meeting donor management goals on the number of organs transplanted per donor: results from the United Network for Organ Sharing Region 5 prospective donor management goals study. Crit Care Med 2012; 40: 2773-80.

17. Wind J, Faut $M$, van Smaalen TC, van Heurn $E W$. Variability in protocols on donation after circulatory death in Europe. Crit Care 2013; DOI: https://doi.org/10.1186/cc13034.

18. Fugate JE, Stadtler M, Rabinstein AA, Wijdicks EF. Variability in donation after cardiac death protocols: a national survey. Transplantation 2011; 91: 386-9.

19. Gardiner D, Wind T, Cole B, et al. European vignettes in donation after circulatory death. Prog Transplant 2017; 27: 28690.

20. Kramer AH, Baht R, Doig CJ. Time trends in organ donation after neurologic determination of death: a cohort study. CMAJ Open 2017; 5: E19-27.

21. Belzak L, Halverson J. Evidence synthesis - the opioid crisis in Canada: a national perspective. Health Promot Chronic Dis Prev Can 2018; 38: 224-33.

22. Kramer AH, Doig CJ. Premortem heparin administration and location of withdrawal of life-sustaining interventions in DCD: lack of high-quality evidence precludes definitive conclusions. Transplantation 2016; 100: e102-3.

23. Munshi L, Dhanani S, Shemie SD, Hornby L, Gore G, Shahin J. Predicting time to death after withdrawal of life-sustaining therapy. Intensive Care Med 2015; 41: 1014-28.

24. Rabinstein AA, Yee AH, Mandrekar J, et al. Prediction of potential for organ donation after cardiac death in patients in neurocritical state: a prospective observational study. Lancet Neurol 2012; 22: 414-9.

25. de Groot YJ, Lingsma HF, Bakker J, Gommers DA, Steverberg E, Kompanje EJ. External validation of a prognostic model predicting time of death after withdrawal of life support in neurocritical patients. Crit Care Med 2012; 40: 233-8.

26. Wind J, Snoeijs M, Brugman CA, et al. Prediction of time of death after withdrawal of life-sustaining treatment in potential donors after cardiac death. Crit Care Med 2012; 40: 766-9.

27. Sarti AJ, Sutherland $S$, Healey A, et al. A multicenter qualitative investigation of the experiences and perspectives of substitute decision makers who underwent organ donation decisions. Prog Transplant 2018; 28: 343-8. 
28. He $X, X u G$, Liang $W$, et al. Nomogram for predicting time to death after withdrawal of life-sustaining treatment in patients with devastating neurological injury. Am J Transplant 2015; 15: 2136-42.

29. Kotsopoulos AM, Bö̈ng-Messing F, Jansen NE, Vos P, Abdo WF. External validation of prediction models for time to death in potential donors after circulatory death. Am J Transplant 2018; 18: $890-6$

30. Hornby L, Dhanani S, Shemie SD. Update of a systematic review of autoresuscitation after cardiac arrest. Crit Care Med 2018; 46: e268-72.

31. Wind J, van Mook WN, Dhanani S, van Heurn EW. Determination of death after circulatory arrest by intensive care physicians: a survey of current practice in the Netherlands. J Crit Care 2016; 31: 2-6.

32. Dhanani $S$, Ward R, Hornby L, et al. Survey of determination of death after cardiac arrest by intensive care physicians. Crit Care Med 2012; 40: 1449-55.

33. CHEO Research Institute; University of Ottawa; Canadian National Transplant Research Program; Canadian Institutes of Health Research; Canadian Critical Care Trials Group; LOEB Chair and Research Consortium. Death Prediction and Physiology after Removal Therapy (DePPaRT) Study. Available from URL: http://www.ddepict.com/deppart-study. html (accessed November 2019).

34. Dhanani $S$, Hornby $L$, Ward $R$, et al. Vital signs after cardiac arrest following withdrawal of life-sustaining therapy: a multicenter prospective observational study. Crit Care Med 2014; 42: 2358-69.

35. NSW Government, Ministry of Health. Organ Donation after Circulatory Death: NSW Guidelines - June 2014. Available from URL: https://www1.health.nsw.gov.au/pds/ActivePDSDo cuments/GL2014_008.pdf (accessed November 2019).

36. Patel S, Martin JR, Marino PS. Donation after circulatory death: a national survey of current practice in England in 2012. Crit Care Med 2014; 42: 2219-24.

37. Kamal L, Lindower J, Kayler LK. Outcomes of kidney transplant recipients from donation after circulatory death donors without preagonal heparin administration. Transplantation 2015; 99: e167-8.

38. Keshava HB, Farver CF, Brown CR, et al. Timing of heparin and thrombus formation in donor lungs after cardiac death. Thorac Cardiovasc Surg 2013; 257: 246-50.

39. Hessheimer AJ, Vendrell M, Munoz J, et al. Heparin but not tissue plasminogen activator improves outcome in donation after circulatory death liver transplantation in a porcine model. Liver Transpl 2018; 24: 665-76.

40. Gill J, Rose C, Lesage J, Joffres Y, Gill J, O'Connor K. Use and outcomes of kidneys from donation after circulatory death donors in the United Sates. J Am Soc Nephrol 2017; 28: 3647-57.
41. Allen MB, Billig E, Reese PP, et al. Donor hemodynamics as a predictor of outcomes after kidney transplantation from donors after cardiac death. Am J Transplant 2016; 16: 181-93.

42. Ho KJ, Owens CD, Johnson SR, et al. Donor postextubation hypotension and age correlate with outcome after donation after cardiac death transplantation. Transplantation 2008; 85: 1588-94.

43. Summers DM, Johnson RJ, Allen J, et al. Analysis of factors that affect outcome after transplantation of kidneys donated after cardiac death in the UK: a cohort study. Lancet 2010; 375: 130311.

44. Reid AW, Harper S, Jackson CH, et al. Expansion of the kidney donor pool by using cardiac death donors with prolonged time to cardiorespiratory arrest. Am J Transplant 2011; 11: 995-1005.

45. Mathur AK, Heimback J, Steffick DE, Sonnenday CJ, Goodrich $N P$, Merion RM. Donation after cardiac death liver transplantation: predictors of outcome. Am J Transplant 2010; 10: 2512-9.

46. Coffey JC, Wanis KN, Monbaliu D, et al. The influence of functional warm ischemia time on DCD liver transplant recipients' outcomes. Clin Transplant 2017; DOI: https://doi. org/10.1111/ctr.13068.

47. Peters-Sengers H, Houtzager JH, Heemskerk MB, et al. DCD donor hemodynamics as predictor of outcome after kidney transplantation. Am J Transplant 2018; 18: 1966-76.

48. Levvey B, Keshavjee S, Cypel $M$, et al. Influence of lung donor agonal and warm ischemic times on early mortality: analyses from the ISHLT DCD Lung Transplant Registry. J Heart Lung Transplant 2019; 38: 26-34.

49. Summers DM, Johnson RJ, Hudson A, Collett D, Watson CJ, Bradley JA. Effect of donor age and cold storage time on outcome in recipients of kidneys donated after circulatory death in the UK: a cohort study. Lancet 2013; 381: 727-34.

50. Aufhauser DD Jr, Wang Z, Murken DR, et al. Improved renal ischemia tolerance in females influences kidney transplant outcomes. J Clin Invest 2016; 125: 1968-77.

51. Gratwohl A, Dohler B, Stern M, Opelz G. H-Y as a minor histocompatibility antigen in kidney transplantation: a retrospective cohort study. Lancet 2008; 372: 49-53.

52. Kim SJ, Gill JS. H-Y incompatibility predicts short-term outcomes for kidney transplant recipients. J Am Soc Nephrol 2009; 20: 2025-33.

53. Kramer AH, Hornby K, Doig CJ, et al. Deceased organ donation potential in Canada: a review of consecutive deaths in Alberta. Can J Anesth 2019; 66: 1347-55.

Publisher's Note Springer Nature remains neutral with regard to jurisdictional claims in published maps and institutional affiliations. 